\title{
Clinical Pattern of Epilepsy and their Electroencephalogram Findings
}

\section{Bhagat $\mathbf{R}^{*}$}

Department of Neurology, College of Medical Sciences, Bharatpur, Nepal

“Corresponding author: Riwaj Bhagat, Department of Neurology, College of Medical Sciences, Bharatpur, Nepal, Tel: +977 9841541364; E-mail: forriwaj@gmail.com

Received date: Nov 26, 2015; Accepted date: Dec 09, 2015; Published date: Dec 16, 2015

Copyright: $\bigcirc 2015$ Bhagat $\mathrm{R}$ et al. This is an open-access article distributed under the terms of the Creative Commons Attribution License, which permits unrestricted use, distribution, and reproduction in any medium, provided the original author and source are credited.

\begin{abstract}
Background: Electroencephalogram (EEG) is a primary diagnostic tool for epilepsy in Nepal. There is virtually rare literature and published data on clinical pattern of epilepsy and their EEG finding in Nepal. Therefore, I attempted to study the clinical pattern of epilepsy and their EEG findings along with the effectiveness of EEG as a primary diagnostic tool for epilepsy and about its other better options.

Methods: A descriptive retrospective study was conducted in tertiary care hospital, Chitwan, Nepal. Demographic profile, provisional diagnosis and EEG findings of epileptic patients between February 2011 to March 2014 were included and descriptive analysis was performed.

Results: The incidence of epilepsy was higher in males than in females $(57.2 \%$ vs. $48.8 \%)$. The majority of patients $(54.7 \%)$ referred for EEG lie in the age group of $11-30$ years. More than half $(61.12 \%)$ of the seizures remained unclassified. Among the classified seizure, the incidence of generalized seizure is higher than partial seizure $(75.85 \%$ vs $23.21 \%)$. Similarly, majority $(55.8 \%)$ of the initial EEG recordings of the patients with provisional diagnosis of epilepsy were found to be normal and more than one third EEG records (38.1\%) were unclassified

Conclusion: Routine twenty-minute EEGs are easy to perform and are well tolerated by patients; however, in more than half of the patients with provisional diagnosis of epilepsy, the initial EEG does not show epileptiform activity and the paroxysmal events due to its low sensitivity. Despite of EEG being the primary diagnostic tool for epilepsy in Nepal, diagnosis should not completely rely on its reading for critically ill patients and for patients with recurrent seizure. Twenty-four hour EEG recording or Video-EEG monitoring (VEEG) or by repeating the routine EEG (up to four recordings) may be a more useful for diagnosis and treatment of epilepsy.
\end{abstract}

Keywords: Diagnosis; EEG; Epilepsy; Nepal

\section{Abbreviations:}

EEG: Electroencephalogram; VEEG: Video Electroencephalogram; IGEs: Idiopathic generalize epilepsy

\section{Background}

Epilepsy is a disorder of the brain that is characterized by a continuing predisposition to generate seizures and by its neurobiological, cognitive, psychological, and social consequences [1]

The electroencephalogram (EEG) is the algebraic summation of electrical activity (excitatory and inhibitory postsynaptic potentials) of the brain as recorded from electrodes placed on the scalp [2]. EEG plays an important diagnostic role in epilepsy and provides supporting evidence of a seizure disorder as well as assisting with classification of seizures and epilepsy syndromes [3]. College of Medical SciencesTeaching Hospital is tertiary neurological centre located at central part of Nepal which treats and manages most of the neurological diseases including epilepsy. Patient with diagnosis of seizure, range from transient loss of consciousness to seizure disorder are referred for EEG recording.

In the context of Nepal, there is virtually rare literature and published data on clinical pattern of epilepsy and their EEG finding.
Here, I have studied the clinical pattern of epilepsy and their EEG finding in patients with Epilepsy. This study could provide the preliminary documented data of clinical classification of epilepsy and their EEG recording in epileptic patients which will give its usefulness in diagnosis and treatment of epilepsy and provide the background for future research.

\section{Methods}

This descriptive retrospective study was conducted at College of Medical Sciences-Teaching Hospital (CMS-TH), Chitwan, Nepal, between February 2011 to March 2014. The study was conducted after obtaining the ethical clearance from the "College of Medical SciencesTeaching Hospital Ethical Review Board". The study does not contain the individual clinical data of any patient. EEG reports of patients with clinical presentation or history of epilepsy/seizure were enrolled in this study. Most of them were referred from the Neurology Department of the institution and some were from other Department as well as from outside CMS-TH. An EEG database had been maintained of all the cases at EEG room, which include demographic profile, provisional diagnosis and EEG findings. All the reports recorded were reviewed by consultant Neurologist and were tabulated. From the total 1777 cases recruited, only 831 cases were included and 946 were excluded from the study. Alcohol withdrawal seizure, EEG referred for other neurological disorder as headache patient with no clinical presentation of seizure/epilepsy and patients with no EEG record were excluded. 
Page 2 of 3

Seizures were classified as partial (simple, complex, secondary generalized and unclassified) seizure, generalized seizure, epilepsy syndrome and unclassified (neither focal nor generalized) on the basis of clinical presentation, clinical history of patients and radiological information. EEG reports were categorized as normal, abnormal-focal, abnormal-generalized and unclassified. The data obtained were used for descriptive analysis. However, all the data were collected from a single tertiary care center of Nepal which can be included as a limitation of the study. Also there can be an interpersonal variability in reporting of EEG reading which can affect the outcome of the study.

\section{Results}

I analyzed 831 epileptic patients and their EEG finding between February 2011 to March 2014. The baseline characteristics are given at (Table 1). Males were affected higher (57.2\%) than females. Majority of patients were $11-20$ years $(29.4 \%)$ and $21-30$ years $(25.3 \%)$. The distribution of clinical pattern of epilepsy shows that most of the patients had unclassified seizure $(61.12 \%)$ followed by generalized seizure (29.5\%) and partial seizure (9\%). Among partial seizure, majority of patients had complex partial seizure (32\%) and unclassified (29.33\%).

\begin{tabular}{|c|c|c|c|}
\hline Characteristics & \multicolumn{2}{|c|}{ Categories } & $\mathrm{n}(\%)$ \\
\hline \multirow{2}{*}{ Gender $(N=831)$} & \multicolumn{2}{|l|}{ Female } & $356(42.8)$ \\
\hline & \multicolumn{2}{|l|}{ Male } & $475(57.2)$ \\
\hline \multirow{8}{*}{$\begin{array}{l}\text { Age in years } \\
(\mathrm{N}=831)\end{array}$} & \multicolumn{2}{|l|}{$<1$} & $26(3.1)$ \\
\hline & \multicolumn{2}{|l|}{$1-10$} & $82(9.9)$ \\
\hline & \multicolumn{2}{|l|}{$11-20$} & $244(29.4)$ \\
\hline & \multicolumn{2}{|l|}{$21-30$} & $210(25.3)$ \\
\hline & \multicolumn{2}{|l|}{$31-40$} & $103(12.4)$ \\
\hline & \multicolumn{2}{|l|}{$41-50$} & $73(8.8)$ \\
\hline & \multicolumn{2}{|l|}{$51-60$} & $41(4.9)$ \\
\hline & \multicolumn{2}{|l|}{$\geq 61$} & $52(6.3)$ \\
\hline \multirow{7}{*}{$\begin{array}{l}\text { Types of epilepsy } \\
\qquad(\mathrm{N}=831)\end{array}$} & \multicolumn{2}{|c|}{ Generalized seizure } & $245(29.5)$ \\
\hline & \multirow{4}{*}{$\begin{array}{l}\text { Partial } \\
\text { seizure }\end{array}$} & Simple partial seizure & $8(1.0)$ \\
\hline & & Complex partial seizure & $24(2.9)$ \\
\hline & & $\begin{array}{l}\text { Seizure with secondary } \\
\text { generalization }\end{array}$ & $21(2.5)$ \\
\hline & & Unclassified partial seizure & $22(2.6)$ \\
\hline & \multicolumn{2}{|c|}{ Epilepsy Syndrome } & $3(0.4)$ \\
\hline & \multicolumn{2}{|c|}{ Unclassified seizure } & $508(61.1)$ \\
\hline \multirow{4}{*}{$\begin{array}{l}\text { EEG reporting } \\
\qquad(\mathrm{N}=831)\end{array}$} & \multicolumn{2}{|c|}{ Abnormal -Focal } & $32(3.9)$ \\
\hline & \multicolumn{2}{|c|}{ Abnormal-Generalized } & $18(2.2)$ \\
\hline & \multicolumn{2}{|l|}{ Normal } & $464(55.8)$ \\
\hline & \multicolumn{2}{|c|}{ Undetermined } & $317(38.1)$ \\
\hline
\end{tabular}

Table 1: Baseline characteristics
Similarly, most of the EEG patterns were found to be normal (55.8) and $38.1 \%$ patterns were undetermined. Among the abnormal EEG recording, there is higher number of abnormal focal.

EEG finding shows that majority of patients with focal seizure were $31-40$ years $(6.8 \%)$ and $1-10$ years (6.1\%). Similarly, generalized seizure was also seen in age group 1-10 years (3.7\%). About 5.3\% of epilepsy provisionally diagnosed as generalized seizure shows focal type of seizure as per the EEG finding. Similarly $3.5 \%$ of unclassified seizure diagnosed provisionally was seen as focal seizure according to EEG finding. EEG finding according to age and epilepsy types are given at (Table 2).

\begin{tabular}{|c|c|c|c|c|c|}
\hline \multirow{3}{*}{\multicolumn{2}{|c|}{ Characteristics }} & \multicolumn{4}{|c|}{ Electroencephalography } \\
\hline & & \multicolumn{2}{|c|}{ Abnormal } & \multirow{3}{*}{$\begin{array}{c}\begin{array}{c}\text { Normal } \\
n(\%)\end{array} \\
12(46.2)\end{array}$} & \multirow{3}{*}{$\begin{array}{l}\text { Unclassified } \\
n(\%)\end{array}$} \\
\hline & & $\begin{array}{l}\text { Focal } \\
\mathrm{n}(\%)\end{array}$ & $\begin{array}{c}\text { Generalized } \\
\mathrm{n}(\%)\end{array}$ & & \\
\hline \multirow{8}{*}{$\begin{array}{l}\text { Age } \\
\text { (years) }\end{array}$} & $<1$ & $1(3.8)$ & 0 & & \\
\hline & $1-10$ & $5(6.1)$ & $3(3.7)$ & $28(34.1)$ & $46(56.1)$ \\
\hline & $11-20$ & $9(3.7)$ & $6(2.5)$ & $126(51.6)$ & $103(42.2)$ \\
\hline & $21-30$ & $7(3.3)$ & $5(2.4)$ & $124(59.0)$ & $74(35.2)$ \\
\hline & $31-40$ & $7(6.8)$ & $2(1.9)$ & $60(58.3)$ & $34(33.0)$ \\
\hline & $41-50$ & $3(4.1)$ & $2(2.7)$ & $49(67.1)$ & $19(26.0)$ \\
\hline & $51-60$ & 0 & 0 & $30(73.2)$ & $11(26.8)$ \\
\hline & $>61$ & 0 & 0 & $35(67.3)$ & $17(32.7)$ \\
\hline \multirow{4}{*}{$\begin{array}{c}\text { Epilepsy } \\
\text { types }\end{array}$} & Generalized & $13(5.3)$ & $7(2.8)$ & $127(51.8)$ & $98(40.0)$ \\
\hline & Partial & $1(1.3)$ & $1(1.3)$ & $51(68.0)$ & $22(29.3)$ \\
\hline & Syndrome & 0 & 0 & $1(33.3)$ & $2(66.67)$ \\
\hline & Unclassified & $18(3.5)$ & $10(1.9)$ & $285(56.1)$ & 195(38.3) \\
\hline
\end{tabular}

Table 2: EEG finding according to age and epilepsy types.

\section{Availability of Data and Materials}

The data supporting the results can be found in Table 1(baseline characteristics) and Table 2(EEG finding according to age and epilepsy types).

\section{Discussion}

This retrospective study analyzed clinical patterns of epilepsy and their EEG finding in clinically diagnosed epileptic patients, from February 2011 to March 2014. The incidence of epilepsy was higher in males than in females ( $57.2 \%$ vs. $48.8 \%)$. A systematic review revealed that epilepsy is slightly more common in men than in women but the sex-specific prevalence is not, in general, significantly different [4]. This difference is usually attributed to male's greater exposure to risk factors for lesional epilepsy and acute symptomatic seizures. However, idiopathic generalize epilepsy (IGEs) are more common in females [5].

The majority of patients (54.7\%) referred for EEG lies in the age groups of 11-30 years indicating higher incidence of epilepsy in young adults. A study of the first 350 cases referred for EEG in Kathmandu 
Page 3 of 3

Medical College Teaching Hospital showed higher (54.4\%) number of patient in the age group of 10-30 years [6]. A systematic review of Asia conclude one peak age for incidence in children and one peak age for prevalence in young adults. However, study done in Shanghai, showed two prevalence age peaks: one between 10 and 30 years old and one in people over 60 years old [4]. The incidence of epilepsy in children and older patient is relatively low in this study. The most probable reason for the missing peak in children and the older age groups patients is the relatively young population compared with other study. Majority of seizures were unclassified. The probable reason may be inadequate patients' history. Among the classified seizure, the incidence of Generalize seizure is higher than partial seizure ( $75.85 \%$ vs. $23.21 \%$ ). Studies showed the range of patients with generalized seizures was $50-$ $69 \%$, and $31-50 \%$ had partial seizures [7-10]. The predominance of generalized epilepsy may be due to inadequate imaging studies and the lack of standardized classification and terminology. Majority (55.8\%) of EEG recording was found to be normal and more than one third EEG records (38.1\%) were unclassified. A routine EEG recording in a patient with epilepsy will have normal activity in about $50 \%$ of cases [5], because of its low sensitivity [3]. Sensitivity could be improved by activation procedures such as hyperventilation, photic stimulation, sleep and sleep deprivation [3]. Further, there may be interpersonal variability in reporting of EEG. Study of EEG interpretation reliability and interpreter confidence: A large single-center study revealed that variability in EEG interpretation is due primarily to how readers interpret specific EEG patterns [11] Moreover, the use of antiepileptic medicines gives rise to normal EEG [12]. Since all the EEG was taken during inter-ictal period, the chances of normal EEG pattern are high. Also, it is crucial to recognize that a normal EEG dose not exclude epilepsy [4]. Yield in adults can be increased by repeating the routine EEG (up to four recordings), and in all ages by use of sleep studies. The combination of wake and sleep records gives a yield of $80 \%$ in patients with clinically confirmed epilepsy [13]. But, in the study it was found none of the EEG recordings were repeated. Also, apart from routine EEG, wake and sleep EEG readings were not done.

Normal, abnormal and unclassified EEG was higher in 10-30 year age groups, due to higher number of patient in these age groups. There is higher frequency of abnormal focal EEG (3.9\%) than abnormal generalized EEG (2.2\%), though clinical diagnosis of seizure showed generalized seizure is more common than the partial seizure. This suggests secondary generalized seizure is often misdiagnosed with generalized tonic clonic seizure. Also $5.3 \%$ of patients with generalized seizure had abnormal focal EEG, which suggests secondary generalized seizure pattern.

\section{Conclusion}

Majority of the epilepsy patients give normal EEG recording and routine EEG has little role in the diagnosis and management of epilepsy due to its low sensitivity. Although, EEG is an essential tool for investigating epilepsy, diagnosis does not completely rely exclusively on its reading. I suggest 24 hours EEG recording or Video-EEG monitoring (VEEG) for critically ill patient and for patients with recurrent seizure instead of use of antiepileptic medications based upon routine EEG. Video-EEG is considered as the gold standard diagnostic tool for sorting out epileptic events versus non-epileptic events. Moreover, video-EEG monitoring in persons with known epilepsy is used to characterize and localize both seizures and interictal activity to help guide management. If not, at least repeating the routine EEG (up to four recordings), and in all ages by use of sleep studies can improve the diagnosis and thereby treatment options for epilepsy.

\section{References}

1. Fisher RS, Van Emde Boas W, Blume W, Elger C, Genton P, et al. (2005) Epileptic seizures and epilepsy: definitions proposed by the International League Against Epilepsy (ILAE) and the International Bureau for Epilepsy (IBE). Epilepsia 46: 470-472.

2. Mac TL, Tran DS, Quet F, Odermatt P, Preux PM, et al. (2007) Epidemiology, aetiology, and clinical management of epilepsy in Asia: a systematic review. Lancet Neurol 6: 533-543.

3. Aminoff MJ (1999) Electroencephalography: General Principals and clinical applications. In: Aminoff MJ. Electrodiagnosis in clinical neurology. (4thedn), Churchill Livingstone, Philadelphia, London, 37-80.

4. Smith SJ (2005) EEG in the diagnosis, classification, and management of patients with epilepsy. J Neurol Neurosurg Psychiatry 76 Suppl 2: ii2-7.

5. Flink R, Pedersen B, Guekht AB, Malmgren K, Michelucci R, et al. (2002) Guidelines for the use of EEG methodology in the diagnosis of epilepsy. International League Against Epilepsy: commission report. Commission on European Affairs: Subcommission on European Guidelines. Acta Neurol Scand 106: 1-7.

6. Shrestha R, Pradhan SN, Sharma SC, Shakya KN, Karki DB, et al. (2003) A study of the first 350 cases referred for EEG in Kathmandu Medical College Teaching Hospital. Kathmandu University medical journal (KUMJ) 2: 24-27.

7. Radhakrishnan K, Pandian JD, Santhoshkumar T, Thomas SV, Deetha TD, et al. (2000) Prevalence, knowledge, attitude, and practice of epilepsy in Kerala, South India. Epilepsia 41: 1027-1035.

8. Tran DS, Odermatt P, Le TO, Huc P, Druet-Cabanac M, et al. (2006) Prevalence of epilepsy in a rural district of central Lao PDR. Neuroepidemiology 26: 199-206.

9. Loh NK, Lee WL, Yew WW, Tjia TL (1997) Refractory seizures in a young army cohort. Ann Acad Med Singapore 26: 471-474.

10. Kwong KL, Chak WK, Wong SN, So KT (2001) Epidemiology of childhood epilepsy in a cohort of 309 Chinese children. Pediatr Neurol 24: 276-282.

11. Grant AC, Abdel-Baki SG, Weedon J, Arnedo V, Chari G, et al. (2014) EEG interpretation reliability and interpreter confidence: a large singlecenter study. Epilepsy Behav 32: 102-107.

12. Salinsky MC, Oken BS, Morehead L (1994) Intraindividual analysis of antiepileptic drug effects on EEG background rhythms. Electroencephalography and clinical Neurophysiology 90: 186-193.

13. Binnie CD (1996) Epilepsy in adults: diagnostic EEG investigation. In: Kimura J, Shibasaki H, eds. Recent advances in clinical neurophysiology. Amsterdam: Elsevier 217-22. 